\title{
Book Review. Anca Luştrea's The psychology of children with auditory disability: development and adaptation (2017, Timisoara: West University Publishing)
}

\section{Ioana DÂRJAN⿳9}

Acknowledging and understanding the complex aspects of hearing impairment or loss in children are of critical importance for all those influenced by it: child itself, family and community, and, of course, professionals (doctors, teachers, therapists, etc.).

A real and efficient educational and social inclusion will require an individualized approach for each child with special needs. In pursuing this objective, the entire society, the community and medical and educational systems should be informed, prepared and

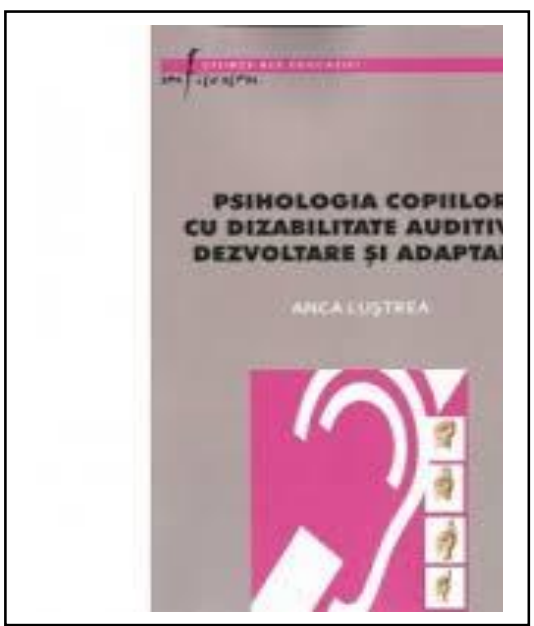
willing to respond responsible and competently to the challenges of raising and educating the child. The specialized and continuously updated approaches enhance the probability of optimal stimulation of child's own developmental potential, improving his chance to a better quality of life, and a higher level of autonomy, involvement and active citizenship as adult.

The book is structured in ten chapters, presenting relevant theoretical and practical information, helpful for parents, teachers, and other categories of helping professionals.

This book is intended as a guide for those involved in the education and social inclusion of children with auditory disorders. It offers expert knowledge about the psychological and developmental particularities of these special children: the specific modalities of perception, memory, information processing, learning, communication, and relationships.

Also, the book indicates the best practices and offers suggestions for better school inclusion and educational, therapeutic and remedial strategies. The author advocates for well-articulated techniques, well-coordinated multidisciplinary teams who can assure child's accommodation, and assistance, through curricular, instructional and environmental adaptation, assistive technology, in multiple context (in family, at school, in community).

\footnotetext{
${ }^{9}$ West University of Timisoara, Educational Sciences Department, $\underline{\text { ioana.darjan@e-uvt.ro }}$
} 
The final conclusions stress the heterogenous development of the children with auditory difficulties and advocate for individualized educational strategies. Another important idea highlighted by the author is the necessity of acknowledging the importance of the family in educational and therapeutic approaches of this children, and the benefits of empowering and involving the family in the process.

The list of references is representative, containing influent papers in the field.

Illustrating the author's theoretical and practical expertise and interests in this topic, this book represents a valuable resource for the field of special education, both for research and applied purposes. 